\title{
La acción didáctica de las Ciencias Sociales y el desarrollo del pensamiento crítico*
}

DOI: http://dx.doi.org/10.17081/eduhum.18.31.1377

Recibido: 18 de marzo de 2016

Aceptado: 26 de agosto de 2016

\section{The didactic action of social sciences and the development of critical thought}

Palabras clave:

Didáctica, Ciencias Sociales, Pensamiento crítico,

Mundo globalizado.

Keywords:

Didactics, Social sciences,

Critical thought,

Global world.

\begin{abstract}
Resumen
El propósito es reflexionar sobre la didáctica de las Ciencias Sociales y el desarrollo del pensamiento crítico en la formación ciudadana del mundo globalizado. Se asume como problema la vigencia de la memorización, como revelación del aprendizaje, cuando se insiste en promover la elaboración del conocimiento desde la integración teórico-práctica. Esta situación determinó estructurar un planteamiento sobre el escenario de la época y la elaboración del conocimiento social, educar el pensamiento crítico en el mundo contemporáneo y el razonamiento como propósito de la acción didáctica de las Ciencias Sociales. Concluye proponiendo el análisis reflexivo de la realidad comunitaria desde un activo pensamiento analítico-constructivo como opción pedagógica para educar al ciudadano que vive el mundo contemporáneo.
\end{abstract}

\begin{abstract}
The main purpose of this study is to point out the didactics of Social Sciences and the development of critical thought along with the formation of citizens in a global world. Memorizing is seen as an issue when acquiring learning, when promoting the elaboration of knowledge from theoretical-practice integration. This situation has driven towards the making of a structural plan about the scenario and about the social knowledge during those times, forming or educating on critical thought in a contemporary world, and reasoning as a purpose of didactic actions in Social Sciences. In the conclusions, it is proposed a reflective analysis of the community reality from an analytical-constructive active thought as a pedagogical option in order to educate the citizen that lives in a contemporary world.
\end{abstract}

\section{(c) $\$$ BY $९$}

Referencia de este artículo (APA): Santiago, J. A. (2016). La acción didáctica de las Ciencias Sociales y el desarrollo del pensamiento crítico. Revista Educación y Humanismo, 18(31), 241-256. http://dx.doi.org/10.17081/eduhum.18.31.1377

\footnotetext{
* Artículo resultado de la investigación: La educación geográfica desde la integración escuela-comunidad y la enseñanza de la geografía, Universidad de los Andes, Venezuela.

1. Doctor en Ciencias de la Educación. Magíster en Docencia Universitaria. Licenciado en Geografía e Historia. Coordinador de la maestría en Educación mención enseñanza de la Geografía, Universidad de los Andes, Venezuela. Email: asantia@ula.ve
} 


\section{Introducción}

Desde fines de la Segunda Guerra Mundial hasta el momento actual se vive una época plena de sucesos, cada vez más sorprendentes y asombrosos, dada la trayectoria, desenvolvimiento e importancia de su repercusión en la dinámica social. Del mismo modo, se han hecho evidentes las notables contradicciones entre los cambios y realizaciones, como es el caso de la revolución económico-financiera y el incremento de la pobreza.

Teniendo como desafío el mejoramiento de la calidad de vida ciudadana, se han gestionado reformas curriculares a fin de renovar pertinentemente la formación educativa conforme a las condiciones del momento histórico. Por ello abundan nuevas opciones pedagógicas y didácticas, cuya firme aspiración es innovar la práctica escolar cotidiana de la enseñanza histórica y geográfica.

De ahí el tema reiterativo en las propuestas curriculares de romper con la exclusividad de la memorización en los procesos de enseñanza y de aprendizaje, por cuanto señalan que es imposible validar el efecto reproductor y la retención de datos en medio de una abierta "explosión de la información" en la "sociedad del conocimiento".

En efecto, cuando se ha intentado mejorar la calidad formativa de las Ciencias Sociales, emerge el obstáculo pedagógico de la memorización, sobre todo porque la forma como se divulgan las noticias, informaciones y conocimientos impide retener en la mente la abundancia de datos a los que se puede tener acceso libremente en la red electrónica.

En los últimos tiempos, el cuestionamiento a esta situación se ha dado ante la necesidad de estimular el pensamiento crítico en la formación pedagógica desde la actividad didáctica de las Ciencias Sociales. Allí, uno de los argumentos sostenidos para promover ese cambio ha sido la exigencia de explicar críticamente los acontecimientos y proponer en ellos, opciones de cambio factibles de originar mutaciones innovadoras.

Así mismo las dificultades sociales del actual momento histórico reclaman el ejercicio habitual del razonamiento analítico-crítico como una tarea constante en la actividad formativa, que debe educar al ciudadano coherentemente con la transformación de la complejidad ambiental, geográfica y social desenvuelta en el inicio del siglo XXI.

\section{El escenario de la época y la elaboración}

\section{del conocimiento social}

Los sucesos que caracterizan el momento histórico desde mediados del siglo XX hasta hoy se han revelado continuamente como hitos revolucionarios en la ciencia y la tecnología, en la economía y las finanzas y en los medios de comunicación social. En ese contexto, llama la atención una realidad que se manifiesta con el aceleramiento del sentido y significado del tiempo, como también en lo difícil de su fisonomía geográfica. 
Lo preocupante es que esa circunstancia despliega condiciones cada vez más complicadas y adversas, con una faz que a simple vista resulta poco entendible bajo la ingenua observación de sus hechos signados de vertiginoso cambio. Esta situación requiere de una interpretación a partir de razonamientos conducentes a descifrar semejantes vicisitudes agitadas e intranquilas. Al reflexionar sobre esta situación Rodríguez (2008) opinó que lo enunciado se exhibe en:

... Una nueva cultura cuyos síntomas más destacados, entre muchos, son el pluralismo, la debilidad de las creencias, el relativismo moral, la carencia de ideologías, una nueva perspectiva en la captación de valores fundamentalmente humanos y en lo que lo efímero y transitorio se opone a lo estable y duradero de la etapa cultural anterior. Cambios que, además, se han producido de forma acelerada y exigen respuestas adecuadas (p.2).

Esta expresión histórica es motivo de atención debido a que allí se ha hecho implícito el valor de lo diverso, lo inestable, lo débil, lo incoherente hasta el "todo vale". Pero también se ha puesto en tela de juicio, por ejemplo, lo riguroso, lo estricto, lo inexorable, lo absoluto y lo infalible; aspectos de significativa importancia en la ciencia desde el siglo XIX hasta fines del siglo $X X$. En consecuencia, se ha afectado lo indudable de la validez y la confiabilidad de la verdad positiva.

En análisis realizado por Souto (2003) sobre la vigencia de los fundamentos decimonónicos, explica que en la actualidad se citan con frecuencia el pensamiento único, la homogeneidad cultural, la certeza de la verdad estereotipada, la resolución de los problemas en forma mecánica, el reduccionismo como práctica para elaborar la verdad, entre otros aspectos.

Al considerar la importancia de estos aspectos originados en el siglo XIX, aunque todavía dominantes en el mundo globalizado, Cornieles (2005) opina que hoy día, son objeto de inestabilidad e inseguridad en el ámbito cambiante y dinámico contemporáneo, donde el conocer es afectado por la falibilidad. A esto se suma que igualmente son trastocados por la divulgación de la información y efecto en la sociedad.

En esta circunstancia llama la atención que la noticia divulgada se convierta en referencia de verdad, en el dato básico para que las personas puedan elaborar puntos de vista sobre los sucesos y donde lo verdadero sea lo percibido y vivido empíricamente. De esta forma, se informa de manera sutil, somera y ligera con la información mediática ofrecida por la televisión, la prensa y/o la radio.

Significa que son los medios los dispositivos comunicadores para divulgar lo indiscutible y lo válido del suceso, donde lo cierto es avalado por la nota e imagen audiovisual del hecho, en su desarrollo natural y espontáneo. En este caso, no hay reflexión ni análisis porque la exposición del caso precisa la evidencia de su existencia, concreción y objetividad. 
Lo interesante de esta circunstancia es la visión parcializada del dato mediático cuyo aparente desarrollo está impregnado de lo nocional y lo superficial, y cada quien lo conoce e interpreta desde su propio punto de vista. Así, bajo un formato de verdad absoluta, el privilegio de la información contribuye a enfatizar el acento neutral, apolítico y desideologizado, en el ámbito del espectáculo, la distracción, la visión simplista del mundo, la vulgaridad, el hedonismo y la banalidad.

Esto se complica porque en la maraña informativa de la "sociedad del conocimiento" y de la "explosión de la información", el positivismo que descarta la vulgaridad tiene dificultades para abordar la complejidad, la incertidumbre, la paradoja, el contrasentido y lo complejo de la divulgación de noticias, informaciones, y reportajes superficiales sobre temas de actualidad. Ese entrecruzamiento de puntos de vista variados y contradictorios enreda aún más el análisis del panorama de la época.

Se impone entonces profundizar el examen sobre esta versión de la realidad originada en los efectos de los medios de comunicación social y sus repercusiones en la elaboración de los criterios personales de los ciudadanos sobre los acontecimientos vividos, pues en el ámbito científico se construye sistemáticamente el conocimiento con el tratamiento de una metodología rigurosa. Al analizar esta situación, Santillán (2008) opina lo siguiente:
Por tanto, el problema a investigar es cómo integrar los elementos de ambas modalidades de formación en un nuevo paradigma centrado en el que aprende. De ahí que las formas que adopte van a depender de las características de los discentes, de sus necesidades formativas, del contexto en que se realiza y, especialmente, en su mismo desenvolvimiento cotidiano (p.73).

Ante estas dos perspectivas para conocer, desde la experiencia y lo científico, la sociedad puede vislumbrar la comprensión de la situación histórica que vive con una nueva racionalidad más coherente a como ocurren los hechos. De tal manera que un espectador ingenuo, apático y desprevenido puede percibir la realidad, el mundo y la vida desde otras opciones, al articular sus saberes vulgares con los aportes de la ciencia y la acción informativa mediática.

El desafío de la elaboración del conocimiento representa dar el salto de la disciplina hacia la interdisciplinariedad. En una explicación que al respecto realizó Morin (1993), él expone lo siguiente: "Claro está que la democratización del derecho a pensar requeriría de una revolución paradigmática que permitiera a un pensamiento complejo reorganizar el saber y reunir los conocimientos hoy tabicados en las disciplinas" (p.192).

En principio lo referido por Morin (1993), implica el desafío de superar la vaguedad como se perciben las situaciones habituales, donde cada 
persona tiene su propia óptica para comprender lo que ve, vive y escucha. Así, en el ámbito de las pluralidades, multiplicidades y diversidades informativas, es necesario asumir otras explicaciones desde razonamientos con argumentos originados en reflexiones analítico-críticas.

Este viraje desde la subjetividad ligera hacia el pensamiento cuestionador debe ser alimentado por el sistemático ejercicio indagador, a la vez que obliga a considerar cambios contundentes en la elaboración del conocimiento, donde inevitablemente se puede conservar la rigidez, la seriedad y el rigor, a pesar de la merma en la exclusividad del positivismo para obtener la verdad.

Pero del mismo modo, es necesario reconocer que emergen otros fundamentos teóricos y metodológicos con una formalidad plena de responsabilidad incuestionable. Se trata de la renovación paradigmática y epistemológica que ha fundado otra opción científica desde los fundamentos de la relatividad. En este sentido, de acuerdo con González y Ojeda (2005):

Jugando en el terreno mismo de las ciencias positivas, las teorías físicas del siglo XX han puesto relatividad, incertidumbre y caos allí donde solo primaban, como criterios del saber supremo, la mecánica, el determinismo y la predictibilidad de los fenómenos, en lógico trasunto de la física newtoniana (s.p.).

Se trata del aporte paradigmático y epistemo- lógico que enfatiza en una remozada reflexión interpretativa desenvuelta en el ámbito de la apertura hacia la conversación informal y el diálogo, de tal manera de viabilizar la emisión y el debate de las ideas. En efecto, eso implica practicar el esfuerzo analítico para descifrar las externalidades y las internalidades de lo real, desde una orientación integral, holística y ecológica.

En esa dirección, se ha hecho necesario asumir la explicación de los objetos de estudio inmersos en el escenario histórico en que ocurren, en su época, sus cambios y transformaciones, así como también se puede revisar desde la visión retrospectiva del presente, el pasado y revelar el proceso que lo ha originado.

La innovación paradigmática y epistemológica enunciada ha facilitado mostrar las circunstancias del acto educante cotidiano; es decir, qué sucede en el aula de clase, a la vez que estimula la reflexión interpretativa sobre las problemática ambientales, geográficas y sociales, desde los puntos de vista de los actores que los protagonizan.

En ese escenario, se muestra la dificultad del atraso epistémico de la escuela donde todavía se evidencia el afecto a preservar la memorización como manifestación del aprendizaje. Esta obsolescencia impide el desarrollo del pensamiento analítico y crítico que pudiese permitir el cuestionamiento a las imágenes y contenidos mediáticos, así como niega la explicación razonada de los contenidos programáticos. 
Como resultado se ha distinguido que la enseñanza se realiza en tres procesos disímiles: a) en la reproducción de nociones y conceptos, cuyo propósito es retener al pie de la letra lo enseñado; b) en lo cotidiano el saber se nutre y transforma con una rapidez inmediata y c) la acción mediática se apoya en la presentación audiovisual atractiva e interesante. Así, la formación del pensamiento crítico está afectada por complicados obstáculos epistemológicos.

Por tanto, esta circunstancia es considerada reiterativamente una parte de la crisis que vive la educación: su discordancia con la época. Así, desde la perspectiva de la vigencia de la memorización, la formación de ciudadanos resulta desfavorable y adversa a las exigencias de educar con responsabilidad, para tener la oportunidad de entender críticamente las circunstancias vividas, plenas de incertidumbre, paradoja y sorpresa.

En el ámbito educativo, el privilegio de la formación de mentes ordenadas, disciplinadas y de respuestas mecanizadas impide las posturas analítico-reflexivas para reflexionar sobre la complejidad informativa mediática y develar el acento infundado y alienador. Lo alarmante es que precisamente, en el aula, con la aplicación de los fundamentos tradicionales de la pedagogía y la didáctica, se contribuye a descontextualizar a los estudiantes de su difícil realidad vivida. En consecuencia:

a) En el mundo contemporáneo se vive un escenario histórico complicado y en crisis permanente donde los cambios y transformaciones en la ciencia y la tecnología y en la economía y las finanzas originan notables efectos y repercusiones en la sociedad.

b) En la presente época es posible para que los grupos humanos estén informados sobre los penosos eventos de las diferentes regiones del planeta con derivaciones que afectan su calidad de vida, aunque sobre ellos tienen sus puntos de vista personales.

c) Hoy día los medios de comunicación social facilitan imágenes, símbolos, códigos e iconos para condicionar la conducta ciudadana y convertir los individuos en espectadores instruidos con poco ejercicio de la reflexión y el análisis.

Al examinar esta situación educativa como rasgo de la época contemporánea, Pérez-Esclarín (2010a) consideró la necesidad de revisar la finalidad educativa y la vigencia del modelo educativo centrado en formar los ciudadanos como eruditos e intelectuales. Desde su perspectiva, esta situación contradice los cambios históricos en desarrollo y, especialmente, la exigencia de la educación humanizadora promotora del ingenio, la inventiva, la creatividad y el cuestionamiento argumentado.

Al respecto, el citado autor propone asumir como objeto de estudio el escenario de lo inmediato, implica prestar atención a los sucesos cotidianos, formar en el intercambio dialógico realizado por los habitantes de la comunidad, con el sentido común, la intuición y la investigación en la calle, pues con estas opciones los ciudadanos 
pueden elaborar su criterio personal sobre la realidad vivida, donde la experiencia se erige como una excelente oportunidad para conocer desde un activo pensamiento.

\section{Educar el pensamiento crítico en el mundo contemporáneo}

Desde mediados del siglo XX se hizo reiterativa la aspiración de la sociedad en el sentido de promover una acción educativa que innovara la formación de los ciudadanos. El cuestionamiento apuntó hacia el modelo centrado en la transmisión de contenidos librescos, con la finalidad de desarrollar las potencialidades intelectuales. $\mathrm{Al}$ respecto, se cuestionó a la memorización como manifestación del aprendizaje.

Sin duda también influyeron los avances científico-tecnológicos, la revolución comunicacional y la renovación paradigmática y epistemológica para colocar en tela de juicio la calidad educativa. Asimismo afectaron a la educación, las nuevas formas de enseñar y aprender, como el acceso a la información y al conocimiento y la elaboración del conocimiento desde la orientación cualitativa de la ciencia.

Esta realidad determinó la exigencia del salto pedagógico y didáctico de reproducir contenidos hacia el estudio de temáticas y problemáticas con el incentivo de la investigación. El propósito esencial de este cambio fue evitar la reproducción del dato conceptual y promover el procesamiento reflexivo con explicaciones argumentadas y analíticas, es decir, agitar la mente concebida como estática por el conductismo.
El viraje educativo obedeció, en opinión de Pérez (2001), a la permanencia del modelo educativo decimonónico en circunstancias sociohistóricas muy particulares y diferentes a épocas anteriores. Allí, llamó la atención que a pesar de realizarse reformas curriculares para adaptar el modelo educativo a los cambios históricos y a las necesidades sociales, la transmisión de contenidos programáticos no se modificó.

Por el contrario, sigue con una asombrosa actualidad la presencia de los comportamientos enciclopedistas, a la usanza del siglo XIX, a pesar de la posibilidad del acceso a la multiplicidad, variabilidad y diversidad de datos, con el apoyo de los dispositivos creados por la impresionante revolución científico-tecnológica para enseñar y aprender. Por sus efectos en la sociedad, esta situación inquietó a Liscano (1997), que señaló lo siguiente:

Lo más especial y desconcertante del mundo informático y comunicacional creado por las nuevas tecnologías y, en especial, la audiovisual ligada a la publicidad, es la homogeneidad lograda en todos los compartimientos humanos, en relación con una escala de valores donde todo queda reducido al valor de la noticia y la masificación de los mensajes... (p.4).

La circunstancia de ofrecer una información poco confiable por su sutil alienación, no le resta importancia ante el hecho de divulgar diariamente acontecimientos adversos que muestran los problemas originados por el deterioro ambiental 
y social; por cierto, notablemente contradictorio con los niveles del beneficio económico-financiero de rentabilidad asombrosa.

En los últimos años esta circunstancia resulta cada vez más inquietante ante el incremento de las dificultades que afectan a las comunidades; en especial, las derivadas de la acción realizada por los ciudadanos para aprovechar el territorio ocupado. De allí el apremio de revisar la calidad formativa de la educación y de manera significativa la enseñanza de las Ciencias Sociales.

Al respecto, se exige el énfasis en lo humano y lo social, pues son las personas como actores que usan, aprovechan y transforman los recursos y potencialidades de la naturaleza. Eso trae como consecuencia considerar la necesidad de revisar el privilegio tradicional asignado a la condición y apuntalar la explicación sobre las formas de intervención de la sociedad y las actividades desarrolladas para mermar la capacidad de lo natural como el escenario originario.

Al estudiar esta circunstancia, Pipkin, Varela y Zenobi (2001) analizan el hecho del acento formativo del determinismo geográfico en la formación social, que sostiene el efecto concluyente de lo natural sobre lo humano. Eso se demuestra desde su punto de vista en el énfasis asignado en la enseñanza sobre los aspectos físico-naturales del territorio y el escaso estudio de los temas referidos a la población y la dinámica social.

Por otra parte, hay un incuestionable afecto a la descripción-narración de los hechos del pasado y también resaltar personajes y acontecimientos puntuales en la identidad nacional. Esa actividad educativa pasa a dejar de lado las explicaciones reveladoras de la causalidad y repercusiones de los sucesos; evita la retrospección analítica y se centra en un pasado-presente impávido donde nada cambia. En efecto, de acuerdo con Pipkin, Varela y Zenobi (2001) se puede apreciar lo siguiente:

Los contenidos que se enseñan cumplían una función útil en el pasado, pero hoy carecen de significatividad. Existen nuevas situaciones, nuevos problemas: resurgimiento de los nacionalismos y de las políticas xenófobas, profundización de las desigualdades sociales y económicas y de los problemas ambientales. Los alumnos los conocen a partir de los medios de comunicación social, pero no siempre pueden interpretarlos, contextualizarlos, ni encuentran relaciones entre ellos y lo que aprenden en la escuela (p.4).

Lo expuesto coloca la enseñanza de las Ciencias Sociales en un escenario pleno de contratiempos por su desfase, diferencia y desacuerdo con las situaciones inciertas, imprevistas e inesperadas, que afectan a las colectividades con repercusiones adversas, hostiles y contraproducentes de suceder cotidiano. Además, evaden el análisis de la conflictividad que merma la calidad de vida a escala planetaria.

Esta realidad representa para el modelo edu- 
cativo, las Ciencias Sociales y los procesos de enseñanza-aprendizaje, la obligación de revisar sus conocimientos y prácticas, en cuanto: a) el comportamiento de las circunstancias del mundo contemporáneo; b) la formación de los ciudadanos en el entendimiento de la realidad vivida y c) la necesidad de potenciar en los individuos la capacidad de imaginar, pensar y comunicar ideas y criterios sobre su mundo, la realidad y la vida.

En efecto, urgen otras formas de conocer; por ejemplo, recientemente, se han valorizado las interpretaciones elaboradas por las personas sobre su realidad, en condición de actores involucrados en la situación vivida. Este hecho es coherente con la renovación paradigmática y epistemológica promovida por la ciencia cualitativa, que estimula entender los hechos desde la experiencia de los actores que los viven.

El propósito es comprender el ámbito histórico o geográfico desde una visión interpretativa y analítica. Por eso es razonable que Weil (1997), a fines del siglo XX, colocara en el primer plano de la formación de la ciudadanía, el fomento del pensamiento crítico ante la urgencia de fortalecer la criticidad y la creatividad, como también la necesidad de repensar la complejidad y diversidad informativa fragmentada y manipuladora.

Entonces, asumir los acontecimientos desde una perspectiva analítica, cuestionadora y transformadora lleva a considerar su carácter histórico y social, por lo que su interpretación no debe ser neutral ni pasiva ni acrítica. De allí el desafío de ir más allá de lo observado en procura de los argumentos que los explican. Es el acto decodificador para descifrar las razones que explican los hechos.

Este acto pedagógico representa para Garrido (2005) la necesidad de ofrecer el acto educante como estímulo a los ciudadanos para resolver sus problemas, a través de la acción pedagógica y didáctica de la investigación. Es vigorizar el sentido y significado de lo social, entender las situaciones con los criterios de los habitantes, valorizar el diálogo, con el contraste de opiniones y ejercitar la indagación en la calle.

Desde su perspectiva, significa reconocer que "la experiencia ha sido obviada por los sistemas formalizados de enseñanza, al tiempo que se ha impedido que la escuela actúe como espacio para potenciar la subjetivación y la socialización de los protagonistas de la educación" (p.140). En la práctica escolar cotidiana, eso supone conocer con procesos de construcción, deconstrucción y reconstrucción de lo real.

Esta situación fue investigada por Santiago (2011), quien encontró que los involucrados en el estudio destacaron que: a) el mundo global está en crisis con pérdida de los valores fundamentales; b) la educación debe adecuarse a esta época de cambios y transformaciones $\mathrm{y}, \mathrm{c}$ ) enseñar Geografía exige promover los valores ciudadanos.

Los aspectos descritos revelan una visión 
significativa sobre la exigencia de la innovación de la enseñanza geográfica, muy afín a lo que expresan los expertos que estudian este campo del conocimiento. Significa que quienes se involucran en los procesos formativos como actores fundamentales, también pueden ofrecer opciones con capacidad transformadora en la enseñanza y aprendizaje de las Ciencias Sociales.

En efecto, se torna imprescindible realizar la lectura comprensiva de los hechos, desde otras perspectivas: como ejercicio del pensar y razonar, que active el pensamiento y la acción reflexiva en forma constante y habitual. Una iniciativa es sustentar el análisis desde sospechar, pensar, imaginar y organizar explicaciones críticas sobre el espacio geográfico, su dinámica histórica y social.

Se impone entonces priorizar sobre el análisis interpretativo de las realidades en la misma forma como ocurren, e implica activar el pensamiento crítico en los procesos de enseñanza y de aprendizaje. Es formar al ciudadano con capacidad de analizar con originalidad y creatividad los hechos de su contexto vivido y evitar la alienación de la acción mediática.

Educar el pensamiento crítico en el mundo contemporáneo significa volver la mirada hacia el aula de clase y dar un viraje a la enseñanza de la Historia, la Geografía y las Ciencias Sociales. El cambio debe apuntar a que la enseñanza y el aprendizaje asuman los objetos de estudio más allá del sentido superficial, pues se desenvuelven en un escenario confuso que amerita del análisis sustentado en la reflexión analítico-crítica.

\section{EI razonamiento como propósito de la ac-} ción didáctica de las Ciencias Sociales

Las emergentes situaciones históricas, geográficas y sociales del mundo contemporáneo, en el inicio del nuevo milenio, encuentran remozados fundamentos teóricos y metodológi$\cos$, fundados en la innovación promovida por la revolución paradigmática y epistemológica en desarrollo, como base para gestionar los cambios pedagógicos y didácticos con capacidad de fomentar el pensamiento crítico.

Las iniciativas en esa dirección, según Quinquer (2001), deben tener el propósito de centrar el esfuerzo formativo del sistema educativo en el desarrollo pedagógico de la acción interpretativa. Un paso esencial debe valorar la importancia asignada a la hermenéutica, con finalidad de dejar ver los argumentos que subyacen en los planteamientos formulados por las personas como actores de la vida cotidiana.

De allí que según el autor citado, la didáctica debe tomar en cuenta la lectura reflexiva de las noticias y las informaciones facilitadas por la televisión, así como las lecturas de referencias bibliográficas. Esta acción debe ser complementada con los puntos de vista expuestos por los estudiantes al respecto. El paso siguiente es comunicar ideas y perspectivas en diálogo abierto, natural y espontáneo. 
Se trata de la valiosa oportunidad de practicar la reflexión hacia la originalidad, la creatividad y la inventiva. Por tanto, en palabras de Cordero y Svarzman (2007) es la complementariedad entre la teoría y la práctica donde la prioridad debe apuntar a considerar tanto el valor educativo de la apertura hacia el entorno inmediato como el valor formativo de la acción interpretativa sostenida en el sentido común y en la intuición.

Más aún, allí se reivindica para el ciudadano la oportunidad de conversar e intercambiar sus puntos de vista y el compartir habitual con los coterráneos de sus pareceres sobre los sucesos vividos y los observados en la acción mediática. Esto representa para González y Ojeda (2005) la afinidad entre la acción formativa escolar y la formación social y la orientación científica.

Entonces se da la acción de humanizar la ciencia democratizando su aplicación didáctica en la elaboración de conocimientos sostenidos en métodos científicos. Eso deriva de aplicar los fundamentos que la ciencia utiliza en construir conceptos y conocer en forma válida y confiable. Asimismo, eso implica sensibilizar a la colectividad sobre el uso de las metodologías de la ciencia en la solución de sus problemas habituales.

Buitrago (2005) al estudiar la educación geográfica coherente con el mundo globalizado opinó que la acción pedagógica y didáctica debe tener como finalidad esencial la formación humanizada de las personas mediante el ejercicio de las posturas críticas y creativas. Es asignar al acto educante su condición de escenario donde se armonizan los fundamentos teóricos y la explicación analítica de la realidad vivida.

Al respecto, también Buitrago (2005) aconseja que el punto de partida debiera ser la comprensión del lugar habitado, como escenario donde la sociedad convive consigo misma y con su territorio. En efecto, entonces se conjugarán experiencias con saberes. Por tanto, ese acervo cultural servirá para entender el lugar vivido, y también para reivindicar el bagaje histórico-cultural comunitario.

Desde este punto de vista, Tobío (2008) destaca la exigencia del abordaje de los sucesos del mundo inmediato, porque esa labor representa la extraordinaria oportunidad para superar la forma como los ciudadanos asignan más importancia a la experiencia que al conocimiento. Se trata del desafío epistémico de revisar la acción pedagógica y didáctica utilizada para facilitar la formación ciudadana reivindicada por el autor mencionado cuando afirmó:

Cuando nos vinculamos con la realidad generalmente le damos más importancia a la experiencia y descartamos los fundamentos teóricos. En consecuencia, seguimos viendo lo mismo con el sentido común y/o la intuición. Al revisar la realidad desde lo empírico la explicación redundará y se evitará penetrar en las incógnitas de lo que veo. Si se acude a la teoría, significa dar importancia al conocimiento científico, bien sean nociones y categorías (s.p.). 
Lo afirmado conduce a entender la importancia de los fundamentos teóricos para comprender los hechos tanto en sus vivencias como en sus explicaciones científicas. Lo factible del cambio será vincular la ciencia con la experiencia. Al igual que desde la experiencia elaborar fundamentos teóricos, con el apoyo de la hermenéutica y fundar una formación educativa con conciencia crítica y constructiva.

En efecto, dado que en la información mediática es común valorar como auténticos ciertos datos superficiales y hasta perversos, con el objeto de manipular la sociedad hacia fines nefastos, la acción didáctica de las Ciencias Sociales deberá afincar su labor formativa en el ejercicio indagador donde lo teórico oriente la experiencia ciudadana y le facilite interpretar lo real con argumentos confiables y rigurosos.

Asimismo es entender que el ciudadano, con su investigación en la calle, y los estudiantes, con sus investigaciones habituales, pueden plantear un discurso interpretativo sobre los sucesos comunitarios, con puntos de vista analíticos sobre sus temáticas y problemáticas de la vida cotidiana, para ofrecer un conocimiento que obligará a revisar la subjetividad ahora sostenida en el pensamiento reflexivo y crítico.

Se trata, según Pérez (2001), del fomento de una formación educativa con capacidad enriquecedora de la experiencia personal que armoniza la teoría con la práctica, en un escenario de permanente transformación del conocer y la posibilidad constante de la transferencia de conocimientos y prácticas, apoyadas en el protagonismo social, para facilitar explicaciones coherentes con lo vivido.

Así, la acción didáctica de las Ciencias Sociales vigorizará el pensamiento crítico que razona interpretativamente, ejercita el aprendizaje crítico y la problematización de las dificultades ambientales, geográficas y sociales. Se trata de la oportunidad de practicar la actividad pensante, como también de estimular la pluralidad de pensamiento y el aperturismo hacia la libertad de pensar con la autonomía de los criterios personales.

Es preciso que en la práctica escolar cotidiana de la enseñanza de la historia, la geografía y las Ciencias Sociales, la actividad reflexiva se convierta en la tarea esencial de sus procesos de enseñanza y de aprendizaje. Eso implica comenzar por revisar el currículo, los programas escolares, los libros y, fundamentalmente, la práctica escolar cotidiana de las asignaturas del área de las Ciencias Sociales.

Para Rajadell (2001) esa tarea evaluativa debe sustentarse en las condiciones del momento histórico, la finalidad educativa asumida, en el paradigma entendido como orientación científica de la actividad formativa y en los fundamentos pedagógicos y didácticos coherentes con la finalidad educativa. En síntesis, es formar a los ciudadanos a tono con la transformación de las necesidades de la sociedad contemporánea. 
Lo anteriormente enunciado incide en considerar que la educación es la base de la transformación de la sociedad. Por tanto, no es privilegiar la memorización como es habitual en la enseñanza y el aprendizaje tradicional, sino educar a los ciudadanos con razonamientos para entender las complicadas situaciones en que se hallan involucrados, no como espectadores sino como actores analíticos.

La reflexión como propósito de la acción didáctica de las Ciencias Sociales significa analizar críticamente las repercusiones de los cambios educativos, en las disciplinas, en los contenidos programáticos y en la práctica escolar cotidiana. Es imperativo que la enseñanza tenga efectos formativos en el aprendizaje crítico, la problematización de los contenidos, la explicación analítica y crítica de los problemas comunitarios.

Desde este planteamiento, en palabras de Pérez-Esclarín (2010b), la acción educativa debe echar las bases de la humanización y sensibilidad social de los ciudadanos y contribuir con el fortalecimiento de la condición humana, afincada en la convivencia, la solidaridad y la ayuda mutua. De esta manera, el pensamiento analítico podrá desempeñar su labor esencialmente humana desarrollando la capacidad interpretativa $\mathrm{y}$ analítica desde una mente activa, ágil y diligente.

En efecto, en la acción didáctica de las Ciencias Sociales, deberá contribuir a educar al ciudadano consciente de su condición humana, de su comportamiento social solidario y el entendi- miento socializado con sus semejantes hacia el mejoramiento de la calidad de vida individual y colectiva. Allí, el apoyo de la actividad pensante será la esencia de la creatividad y el desarrollo personal y social en un ambiente sano y equilibrado.

\section{Conclusión}

La exigencia de contribuir al desarrollo del pensamiento crítico amerita prestar atención al acto de promover la modernización pedagógica, con la finalidad de orientar los procesos de enseñanza y de aprendizaje hacia una formación más centrada en convertir el acto educante en una oportunidad para explicar el lugar, desde los razonamientos analíticos y críticos del habitante activo en su desempeño ciudadano.

Es fomentar el protagonismo colectivo apoyado en la reflexión analítica y crítica, además de motivar la creatividad, la iniciativa emprendedora y transformadora. Eso supone, de acuerdo con Lombardi (1993), revisar la confusión entre información y conocimiento, falsedad y verdad, error y certeza; en otras palabras, adiestrados por la verdad absoluta, de pronto existe la verdad inestable.

Esta labor debe traducirse, en palabras de Santiago (2008), en enseñar a respetar los modos de pensar y la pluralidad del pensamiento; entender que la diversidad conceptual debe sustentarse en presupuestos validadores de la legitimidad y coherencia del análisis científico; adquirir conocimientos desde la actividad investigativa, donde las teorías se armonizan con la práctica. 
Esta orientación pedagógica debe representar, en palabras de Rajadell (2001), lo siguiente: "Una enseñanza activa es aquella que busca despertar el interés de los alumnos, de motivarlos a hacerse preguntas y buscarles respuestas y de contribuir a que ellos pongan en marcha procesos cognitivos que lleven a la construcción de aprendizajes significativos" (p.465).

De allí la importancia asignada a actividades didácticas, tales como: la lectura interpretativa, la escritura analítica y el discurso crítico, y también manifestar en forma oral la subjetividad elaborada y activar la mente con un razonamiento que exprese el pensamiento analítico, explicativo y expresivo de la autonomía de criterios sobre los objetos de estudio.

Desde esta acción formativa, de acuerdo con Pérez-Esclarín (2010b), es mejorar la capacidad de formar ciudadanos en un ámbito de convivencia social donde se aprenda el respeto a los demás, analizar las circunstancias desde razonamientos personales argumentados desde sus propios puntos de vista, y también echar las bases de una postura de habitante comprometido con la responsabilidad social.

Por tanto, el autor citado opina: "Esto va a requerir, entre otras cosas, métodos didácticos participativos que favorezcan el pensamiento crítico y autónomo y promuevan la solidaridad y el servicio... No olvidemos que los valores se aprenden, sobre todo, en la práctica, en el ejercicio diario..." (p.5). Así, el pensamiento crítico deberá incentivar la transferencia del conocimiento científico para explicar la realidad.

Lo anterior supone conocer científicamente; el pensamiento estará permanentemente involucrado en ese ir y venir del proceso constructivo del conocimiento, desenvuelto en el despliegue de la teoría y la práctica. Se trata, en palabras de Weil (1997), visibilizar lo oculto para entender lo visible, desde la visión retrospectiva en donde se formó.

Esta acción hermenéutica deberá revisar lo que sucede, como escenario de la convivencia humana y social. La actividad tendrá como propósito facilitar la lectura interpretativa desde el análisis crítico, el compromiso social y la conciencia crítica, al participar en forma activa en el desarrollo de procesos pedagógicos creativos, orientados por la formulación de preguntas para guiar el análisis explicativo.

Podría afirmarse que en las condiciones sociohistóricas del mundo contemporáneo, la acción didáctica de las Ciencias Sociales tiene la responsabilidad de estimular el pensamiento crítico ante el incesante afán mediático por desviar la atención sobre la compleja realidad. Así, el reto será alfabetizar a los ciudadanos en forma coherente con las complicadas y adversas situaciones que merman su calidad de vida.

Por lo expuesto, se impone motivar el pensamiento crítico, formar personas con criterios propios y fundamentar la democracia donde se edu- 
quen ciudadanos emprendedores y laboriosos. El desafío de comprender la enrevesada realidad de la época contemporánea requiere modernizar la enseñanza y el aprendizaje acordes con el actual escenario histórico difícil, pero pleno de oportunidades para hacer factible el cambio y la transformación constructiva.

\section{Referencias}

Buitrago B., O. (2005). La educación geográfica para un mundo en constante cambio. $B i$ blio $3 W$ Revista Bibliográfica de Geografía y Ciencias Sociales, 10(561). Recuperado desde: http://www.ub.es/geocrit/ b3w-561.htm

Cordero, S. \& Svarzman, J. (2007). Hacer geografía en la escuela. Buenos Aires, Argentina: Ediciones Novedades Educativas.

Cornieles, E. (2005, noviembre 15). Educación en la globalización. Diario Panorama.

Garrido P., M. (2005). El espacio por aprender, el mismo que enseñar: Las vigencias de la educación geográfica. Cuadernos Cendes, 25(66), 137-163.

González, J. C. \& Ojeda, J. F. (2005). Biblio 3W, Revista Bibliográfica de Geografía y Ciencias Sociales, 10(618). Recuperado desde http://www.ub.es/geocrit/b3w-618. htm

Liscano, J. (1997, enero 10). La modernidad es cada vez más moderna. Diario El Nacional, p.A-4.

Lombardi, A. (1993, febrero 25). Cultura y contemporaneidad. Diario El Nacional, p.A-4.
Morin, E. (1993). El método I: La naturaleza de la naturaleza. Madrid: Cátedra.

Pérez, E. (2001). Enseñanza y cultura escolar. Revista de Teoría y Didáctica de las Ciencias Sociales, 6, 103-114.

Pérez-Esclarín, A. (2010a). Educación y globalización (2a ed.). Caracas: Editorial San Pablo.

Pérez-Esclarín, A. (2010b, junio 6). Educar para la ciudadanía. Diario Panorama, pp.1-5.

Pipkin, D., Varela, C. \& Zenobi, V. (2001). Aportes para el debate curricular. Enseñanza de las Ciencias Sociales. Buenos Aires: Secretaría de Educación. Dirección de Currículo. Gobierno de la Ciudad Autónoma de Buenos Aires.

Quinquer, D. (2001). El desarrollo de habilidades lingüísticas en el aprendizaje de las Ciencias Sociales. Revista Iber. Didáctica de las Ciencias Sociales, Geografía e Historia, 28, 9-40.

Rajadell, N. (2001). Los procesos formativos en el aula. Estrategias de enseñanza-aprendizaje. Didáctica general para psicopedagogos. Madrid: Universidad de Educación a Distancia (Uned).

Rodríguez, M. Á. (mayo de 2008). Una enseñanza nueva en una cultura nueva. El caso de la geografía en el bachillerato. Trabajo presentado en el X Coloquio Internacional de Geocrítica. Universidad de Barcelona, Barcelona, España.

Santiago, C. (octubre de 2008). Reflexiones ante discursos mediático-políticos sobre temas geográficos. Panel "La cuestión ambiental”. Trabajo presentado en el X Encuen- 
tro Internacional Humboldt, Rosario, Argentina.

Santiago, J. A. (2011). La orientación pedagógica de la Geografía en opinión de estudiantes de formación docente. Revista Educación y Humanismo, 13(20), 95-108.

Santillán C., F. (2008). El papel del profesor ante las modalidades educativas no convencionales. Revista Educación y Humanismo, 14, 68-82.

Souto, X. M. (2003). Retos sociales, propuestas educativas e innovación didáctica. Conferencia en las Primeras Jornadas de Didác- tica en la Universidad del Cuyo. Mendoza, Argentina.

Tobío, O. (octubre de 2008). De la disyuntiva al dilema de la investigación en geografia: apuntes para pensar el legado disciplinar y la formación y práctica de los profesores. Trabajo presentado en el 1er. Encuentro de Graduados en Geografía, UBA. Universidad de Buenos Aires, Buenos Aires.

Weil, P. (1997). Holística. Una nueva visión y abordaje de lo real. Santafé de Bogotá, Colombia: Editorial San Pablo. 